\title{
Optimal Timing of Laparoscopic Cholecystectomy After Endoscopic Retrograde Cholangiopancreatography
}

\author{
Guru Prasad Reddy Gorla ${ }^{\mathrm{a}}$, Alfred J Augustine ${ }^{\mathrm{a}, \mathrm{b}}$, Shibumon Mundunadakal Madhavan ${ }^{\mathrm{a}}$
}

\begin{abstract}
Background: Endoscopic retrograde cholangiopancreatography (ERCP) followed by laparoscopic cholecystectomy (LC) comprises the current treatment modality in patients with common bile duct (CBD) stones. The optimum interval between ERCP and LC is a topic of debate.
\end{abstract}

Methods: A total of 50 patients underwent LC following ERCP from December 2011 to October 2013. Of these, 28 patients underwent surgery within 3 days of ERCP (early) and 22 patients beyond 3 days following ERCP (delayed). A prospective observational study of various technical difficulties encountered (operative duration, adhesions, frozen Calot's, bile duct injuries, conversion rate and need for drain) was done and comparison was done.

Results: The incidence of adhesions, frozen Calot's, cystic duct injury, need for drain placement and the mean operative duration and postoperative stay were significantly higher in the delayed group. The conversion rate though higher is not statistically significant.

Conclusion: The longer the interval between ERCP and LC, the higher are the chances of encountering complications and the risk of conversion to open technique as well as the need for increased hospital stay following surgery. Early LC following ERCP is preferred.

Keywords: Laparoscopic cholecystectomy; Endoscopic retrograde cholangiopancreatography; Choledocholithiasis

Manuscript accepted for publication May 21, 2014

${ }^{a}$ Division of General Surgery, Kasturba Medical College, Manipal University, Mangalore 575002, India

${ }^{\mathrm{b}}$ Corresponding Author: Alfred J Augustine, Department of General Surgery, Kasturba Medical College, Manipal University, Mangalore 575002, India. Email: alfaugustine@yahoo.com

doi: http://dx.doi.org/10.14740/jcs230w

\section{Introduction}

Studies have shown that laparoscopic cholecystectomy (LC) following endoscopic retrograde cholangiopancreatography (ERCP) is more difficult than LC for uncomplicated cholelithiasis $[1,2]$. The usual indication for ERCP is biliary pancreatitis [3], which causes inflammation in the pericholedochal region leading to adhesions. The use of contrast in ERCP also elicits an inflammatory reaction around the common bile duct (CBD) and sphincterotomy leads to bacterial colonization causing inflammation and scarring of the hepatoduodenal ligament leading to adhesions and frozen Calot's $[2,4]$. This theory of bacterial colonization is supported by the finding that bacteria have been isolated from bile in $60 \%$ of patients who underwent ERCP with sphincterotomy [4, 5]. A significantly higher conversion rate was encountered when LC was done 2 - 6 weeks after ES, as compared to 1 week after ERCP [6]. Reports of LC done within days following ERCP show conversion rates as low as those for patients with uncomplicated cholelithiasis [6].

There are not many studies on the timing of LC following ERCP. This study is aimed at comparing the various technical difficulties encountered during LC following ERCP, in the early period and after an interval, to decide upon the optimal timing for the surgery.

\section{Methods}

A prospective observational cohort study was conducted in the hospitals of Kasturba Medical College, Mangalore and all the patients who underwent LC following ERCP from December 2011 to October 2013 were included. Patients were divided into two groups, those undergoing LC within 3 days of ERCP (early) and beyond (delayed). A detailed pro forma was developed to record information regarding patient's age, sex, date of admission, date of discharge, date of surgery, intraoperative findings and the various technical difficulties encountered.

Patients undergoing LC along with other laparoscopic intervention in the same setting, $\mathrm{LC}$ with $\mathrm{CBD}$ exploration, 


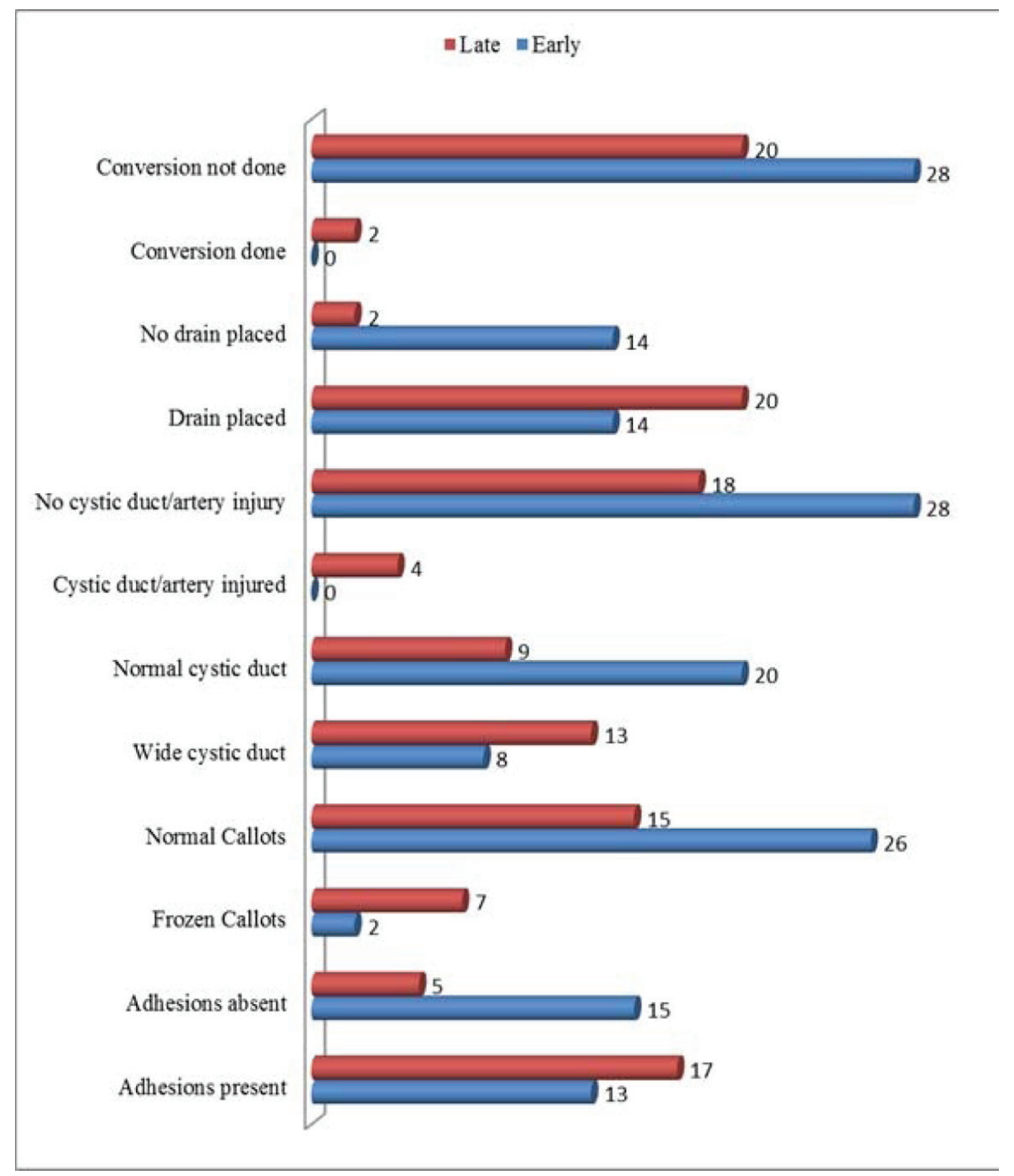

Figure 1. Frequency of complications encountered in early and delayed groups.

LC in gallbladder carcinoma and patients with cardiovascular or pulmonary disease, coagulopathy, end stage liver disease and patients who underwent previous upper abdominal surgeries were excluded.

All patients with symptomatic gallstones with suspected choledocholithiasis had been evaluated by ERCP by one of the three medical gastroenterologists and CBD cleared of stones followed by stent placement routinely. LC was performed using standard four port technique. Duration of surgery was calculated from the time of insertion of the first trocar till closure of all the port sites. The various intraoperative difficulties encountered were tabulated and compared between the two groups.

Statistical analysis was performed using SSPS (Statistical Package For Social Sciences) software version 18. Parametric data have been measured as means and standard deviations. Nonparametric data are measured as frequencies and percentages. Continuous data have been analyzed using paired $t$ test and non-continuous data by Fisher's exact test.

\section{Results}

During the course of the study, a total of 50 patients were included who underwent LC following ERCP among which, 28 patients underwent LC within 3 days of ERCP (early) and 22 patients underwent the surgery beyond 3 days (delayed). Delay in operation has been due to the referral system.

Most patients were in the age group of 41 - 60 (44\%). There was no increased rate of conversion or complications associated with age variation. The frequency of various complications studied was higher in the delayed group (Fig. 1).

Omental adhesions and bowel adhesions to the gallbladder wall were noted in $60 \%$ of the patients. In early group, 
Table 1. Age Distribution and Mean Operative Duration and Postoperative Stay

\begin{tabular}{|c|c|c|c|c|c|c|c|}
\hline Group ERCP & $\mathbf{N}(\mathrm{pts})$ & Min & $\operatorname{Max}$ & Mean & Std & t value & $\mathbf{P}$ \\
\hline \multicolumn{8}{|l|}{ Post ERCP } \\
\hline Age (years) & & & & & & 2.439 & $0.018 \mathrm{sig}$ \\
\hline Early & 28 & 18 & 75 & 43.18 & 15.88 & & \\
\hline Late & 22 & 23 & 74 & 53.41 & 13.09 & & \\
\hline Total & 50 & 18 & 75 & 47.68 & 15.45 & & \\
\hline Duration (min) & & & & & & 2.150 & $0.037 \mathrm{sig}$ \\
\hline Early & 28 & 40 & 165 & 81.25 & 31.20 & & \\
\hline Late & 22 & 55 & 190 & 100.91 & 33.22 & & \\
\hline Total & 50 & 40 & 190 & 89.90 & 33.27 & & \\
\hline Postoperative stay (days) & & & & & & 2.077 & $0.043 \mathrm{sig}$ \\
\hline Early & 28 & 1.000 & 6.000 & 2.50 & 1.37 & & \\
\hline Late & 22 & 1.000 & 7.000 & 3.32 & 1.39 & & \\
\hline Total & 50 & 1.000 & 7.000 & 2.86 & 1.43 & & \\
\hline
\end{tabular}

$46.4 \%(13 / 28)$ of patients and 77\% (17/22) in delayed group were observed to have the adhesions (P value: 0.027 ).

In nine patients, there was difficulty in Calot's triangle dissection of which seven belonged to the delayed group and two from the early group (P value: 0.024$)$.

Wide and short cystic duct leading to difficult clipping has been observed in 21 (42\%) of the patients. Among them, $28.5 \%(8 / 28)$ were in the early group and 59\% (13/22) were in the late group (P value: 0.030$)$.

Accidental/inadvertent injury to the cystic duct or artery were seen in four $(8 \%)$ instances, all in the delayed group ( $\mathrm{P}$ value: 0.032 ).

A total of $34(68 \%)$ patients needed placement of drain due to excessive dissection.

Half of the patients in early group needed the drain whereas 91\% (20/22) of the patients in the delayed group needed a drain (P value: 0.002).

In the delayed group $9.1 \%$ patients needed conversion to open procedure. There were no conversions in the early group ( $\mathrm{P}$ value: 0.189 ).

In the early group $35.7 \%$ of the patients and $36.4 \%$ in the delayed group had an associated comorbidity (diabetes or hypertension) (P value: 0.962).

The mean operative time in the early group was $81 \pm 31$ min and in the delayed group was $101 \pm 33$ min ( $\mathrm{P}$ value: 0.037). The mean postoperative hospital stay in the early group was $2.5 \pm 1.37$ days and in the delayed group was 3.32 \pm 1.39 days ( $\mathrm{P}$ value: 0.043 ) (Table 1$)$.
There were no mortalities or CBD injuries in either group.

\section{Discussion}

In 1968, McCune, a surgeon, reported the endoscopic technique of visualizing of the common bile and pancreatic duct. With the introduction of endoscopic sphincterotomy in 1974, therapeutic pancreaticobiliary endoscopy subsequently was developed [7].

In our hospital, ERCP with endoscopic sphincterotomy (ES) and stent placement followed by LC is routinely performed whenever choledocholithiasis is suspected. This is supported by the evidence from a randomized control trial conducted by Boerma et al [2] which states a wait and watch policy is not recommended after sphincterotomy in choledocholithiasis. In their study, $47 \%$ of patients, managed conservatively, developed at least one recurrent biliary complication and $37 \%$ needed cholecystectomy at a later date.

In studies by Lau et al [8] and Costi et al [9], ERCP followed by LC was advocated for choledocholithiasis because of greater long-term morbidity and mortality in the ERCP alone group.

Salman et al [4] in their study on the timing of LC following ERCP, stated that after $72 \mathrm{~h}$, the inflammation makes surgery more difficult in patients and recommended performing LC within 24 - $72 \mathrm{~h}$ after ERCP. Our study proves 
this by showing statistically significant differences in the occurrence of adhesions, frozen Calot's, wide cystic duct, cystic duct/artery injury as the interval between ERCP and LC progresses.

Anandi et al [10], in their study concluded that cholecystectomy within 1 week after ES may prevent recurrent biliary complications in the majority of cases and reduce the postoperative hospital stay. Akaraviputh et al [11], in their study proved that same day approach for choledocholithiasis using endoscopic stone removal followed by LC is preferable. Zang et al [12] recommended that early LC after endoscopic CBD stone extraction in developing countries is feasible and safe and also reduces the total hospital cost effectively.

In our study, the chance of encountering adhesions was noted to significantly increase with age ( $P$ value 0.021 ). Increasing age is associated with an increased probability of multiple attacks of cholecystitis and thereby increased incidence of fibrosis and adhesions in the Calot's triangle. Randhawa et al [13] found that age more than 50 years is associated with the same difficulties. The risk of facing a frozen Calot's is also more as the interval between ERCP and LC increases (P value 0.024). Ishizaki et al [14] in their study found post ERCP status to be a significant predictor of difficulty in adhesiolysis and Calot's triangle dissection.

One of the well known causes of cystic duct stump leakage is a wide cystic duct. It is understood that after an episode of biliary pancreatitis the cystic duct can be edematous and clips can be hard to place and easily slip $[15,16]$. When encountered with a wide cystic duct, we applied larger clips or used absorbable sutures to suture ligate the duct before division. There was a significant association of wide cystic duct in the late ERCP group (59\%) compared to the early group $(28.5 \%)$ (P value 0.030$)$.

According to Contini et al [17], the indication for a drain placement is due to the worry about a biliary leakage or hemorrhage from gall bladder bed following excess dissection. Thus, situations associated with difficulty in dissection also are associated with the use of drain. This may not be associated independently with the above predictors. A total of $68 \%$ of the patients undergoing LC following ERCP needed placement of a drain. Need for a drain was significantly higher as the interval between ERCP and LC progressed (P value 0.002 ).

In the present study, the mean operative time in the early group was $81 \pm 31 \mathrm{~min}$ and in the delayed group was 101 $\pm 33 \mathrm{~min}$, i.e. the mean operative time in the early group is shorter than that of the delayed group and this was similar with the results of the study done by Csendes et al [5]. The operating time was longer in patients who underwent delayed cholecystectomy ( $\mathrm{P}$ value 0.037 ), possibly due to scarring and fibrosis of the biliary tree and Calot's triangle which make the surgeon very cautious during dissection of the junction between cystic duct, common hepatic duct and
CBD.

In our study, the mean length of postoperative hospital stay in the early group $(2.5 \pm 1.37$ days $)$ was significantly lower than that of the delayed group (3.32 \pm 1.39 days $)$ and this also was in accordance with a study by Donkervoort et al [6] who found significant reduction in the hospital stay. The patients in the delayed group have significantly longer hospital stay than patients in the early group, which may be due to more postoperative complications in the delayed group $(\mathrm{P}$ value 0.043 ).

Our study shows, a higher conversion rate was encountered when LC was performed beyond 3 days following ERCP ( $\mathrm{P}$ value 0.189 , not statistically significant). There were no conversions in the early group and two patients needed conversion to open cholecystectomy in the delayed group. Studies on LC performed within days after ERCP show conversion rates as low as those for patients with uncomplicated cholelithiasis and our study is similar to the study by Bostanci and colleagues [18] who found significant reduction in the conversion and the conversion rate was mostly due to inflammatory adhesions.

\section{Conclusion}

In conclusion, the optimum time to perform LC is within 3 days after ERCP. The longer the interval between ERCP and LC, the higher are the chances of encountering complications and increased need for conversion as well as prolonged operating time and hospital stay.

Though LC following ERCP is the gold standard for choledocholithiasis in the current general surgical practice, the operating surgeon should always be wary of the various technical difficulties encountered. Knowledge of these challenges will enable the surgeon in providing a safer and more favorable outcome in cholecystectomy.

\section{Author Contributions}

Guru Prasad proposed the study. Alfred Augustine and Shibumon performed research and wrote the first draft. Guru Prasad collected and analyzed the data. All authors contributed to the design and interpretation of the study and to further drafts. Alfred Augustine is the guarantor.

\section{Funding}

No funds have been received.

\section{Ethical Approval}

Not needed. 


\section{Competing Interest}

No benefits in any form have been received or will be received from a commercial party related directly or indirectly to the subject of this article.

\section{References}

1. Reinders JS, Gouma DJ, Heisterkamp J, Tromp E, van Ramshorst B, Boerma D. Laparoscopic cholecystectomy is more difficult after a previous endoscopic retrograde cholangiography. HPB (Oxford). 2013;15(3):230-234.

2. Boerma D, Rauws EA, Keulemans YC, Janssen IM, Bolwerk CJ, Timmer R, Boerma EJ, et al. Wait-and-see policy or laparoscopic cholecystectomy after endoscopic sphincterotomy for bile-duct stones: a randomised trial. Lancet. 2002;360(9335):761-765.

3. Lakatos L, Mester G, Reti G, Nagy A, Lakatos PL. Selection criteria for preoperative endoscopic retrograde cholangiopancreatography before laparoscopic cholecystectomy and endoscopic treatment of bile duct stones: results of a retrospective, single center study between 1996-2002. World J Gastroenterol. 2004;10(23):34953499.

4. Salman B, Yilmaz U, Kerem M, Bedirli A, Sare M, Sakrak O, Tatlicioglu E. The timing of laparoscopic cholecystectomy after endoscopic retrograde cholangiopancreaticography in cholelithiasis coexisting with choledocholithiasis. J Hepatobiliary Pancreat Surg. 2009;16(6):832-836.

5. Csendes A, Burdiles P, Maluenda F, Diaz JC, Csendes P, Mitru N. Simultaneous bacteriologic assessment of bile from gallbladder and common bile duct in control subjects and patients with gallstones and common duct stones. Arch Surg. 1996;131(4):389-394.

6. de Vries A, Donkervoort SC, van Geloven AA, Pierik EG. Conversion rate of laparoscopic cholecystectomy after endoscopic retrograde cholangiography in the treatment of choledocholithiasis: does the time interval matter? Surg Endosc. 2005;19(7):996-1001.

7. Phillips MS, Marks JM. Endoscopic Retrograde Cholangiopancreatography: General Principles. The SAGES Manual. 2012;411-425.

8. Lau JY, Leow CK, Fung TM, Suen BY, Yu LM, Lai $\mathrm{PB}$, Lam YH, et al. Cholecystectomy or gallbladder in situ after endoscopic sphincterotomy and bile duct stone removal in Chinese patients. Gastroenterology. 2006;130(1):96-103.

9. Costi R, DiMauro D, Mazzeo A, Boselli AS, Contini S, Violi V, Roncoroni L, et al. Routine laparoscopic cholecystectomy after endoscopic sphincterotomy for choledocholithiasis in octogenarians: is it worth the risk? Surg Endosc. 2007;21(1):41-47.

10. Schiphorst AH, Besselink MG, Boerma D, Timmer R, Wiezer MJ, van Erpecum KJ, Broeders IA, et al. Timing of cholecystectomy after endoscopic sphincterotomy for common bile duct stones. Surg Endosc. 2008;22(9):2046-2050.

11. Akaraviputh T, Rattanapan T, Lohsiriwat V, Methasate A, Aroonpruksakul S, Lohsiriwat D. A same day approach for choledocholithiasis using endoscopic stone removal followed by laparoscopic cholecystectomy: a retrospective study. J Med Assoc Thai. 2009;92(1):8-11.

12. Zang J, Zhang C, Zhou H, Gao J. Early laparoscopic cholecystectomy after endoscopic common bile duct stone extraction: the experience from a developing country. Surg Laparosc Endosc Percutan Tech. 2011;21(2):120122.

13. Randhawa JS, Pujahari AK. Preoperative prediction of difficult lap chole: a scoring method. Indian J Surg. 2009;71(4):198-201.

14. Ishizaki Y, Miwa K, Yoshimoto J, Sugo H, Kawasaki S. Conversion of elective laparoscopic to open cholecystectomy between 1993 and 2004. Br J Surg. 2006;93(8):987-991.

15. Shaikh IA, Thomas H, Joga K, Amin AI, Daniel T. Postcholecystectomy cystic duct stump leak: a preventable morbidity. J Dig Dis. 2009;10(3):207-212.

16. Reinders JS, Goud A, Timmer R, Kruyt PM, Witteman BJ, Smakman N, Breumelhof R, et al. Early laparoscopic cholecystectomy improves outcomes after endoscopic sphincterotomy for choledochocystolithiasis. Gastroenterology. 2010;138(7):2315-2320.

17. Contini S, Dalla Valle R. [Laparoscopic cholecystectomy: a need to drain?]. Acta Biomed Ateneo Parmense. 1992;63(3-4):237-241.

18. Bostanci EB, Ercan M, Ozer I, Teke Z, Parlak E, Akoglu M. Timing of elective laparoscopic cholecystectomy after endoscopic retrograde cholangiopancreaticography with sphincterotomy: a prospective observational study of 308 patients. Langenbecks Arch Surg. 2010;395(6):661-666. 